\title{
Predictive factors of the general public's willingness to be seen and seek treatment from a nurse practitioner in Australia: a cross-sectional national survey
}

\author{
Trudy Dwyer ${ }^{1^{*}} \mathbb{D}$, Alison Craswell ${ }^{2}$ and Matthew Browne ${ }^{3}$
}

\begin{abstract}
Background: Health care delivery in Australia is experiencing challenges with services struggling to keep up with the increasing demands of an aging population, rising levels of chronic disease and limited funding for care. Where adjunct models of health care such as the Nurse Practitioner (NP) have the potential to address this gap, in Australia, they remain an underutilised service. Clarifying the nature of the consumers 'willingness' to be seen by NPs warrants further investigation.
\end{abstract}

Methods: Australia-wide, cross-sectional population-based survey was undertaken using computer-assisted telephone interviewing technique.

Results: While just over $53 \%$ of the general public participants $(n=1318)$ had heard of an NP, once they became aware of their scope of practice, the majority agreed or strongly agreed they were willing to be seen by an NP in the community (91.6\%), the emergency department $88.2 \%$ ), to manage chronic conditions (86\%), to have scrips written and referrals made (85.3\%), and if they did not have to wait so long to see a medical doctor (81\%). Factors significantly predicting willingness were being: female, less than 65 years of age, native English speakers, or residents from town/ regional and rural settings.

Conclusion: Despite limited awareness of the NP role, a large proportion of the Australian population, across different demographic groups, are willing to be seen and treated by an NP. Expansion of this role to support medical services in areas of need could improve healthcare delivery.

Keywords: Australia, National survey, Nurse practitioner, Consumer satisfaction, Consumer choice, Consumer experience

\section{Background}

Australia, like other countries in the developed world, is experiencing increased demand on the health care system. This demand is characterized by higher numbers of patient presentations and congestion in emergency

\footnotetext{
*Correspondence: t.dwyer@cqu.edu.au

${ }^{1}$ CQUniversity Australia, Building 18 Rockhampton Campus, Bruce Highway, Rockhampton Q 4702, Australia

Full list of author information is available at the end of the article
}

departments, and long wait times to see the medical doctor/practitioner (MD) $[1,2]$. Factors contributing to this issue are the increased proportion of the population who are older, have chronic or multiple health problems and who experience difficulty accessing timely or cost-effective primary health care such as general medical practitioners (GP) [2-7]. It is anticipated that this increasing demand for access to an already stretched primary health care services will not ease soon [8]. Internationally, health workforce shortages necessitate the implementation of original author(s) and the source, provide a link to the Creative Commons licence, and indicate if changes were made. The images or other third party material in this article are included in the article's Creative Commons licence, unless indicated otherwise in a credit line to the material. If material is not included in the article's Creative Commons licence and your intended use is not permitted by statutory regulation or exceeds the permitted use, you will need to obtain permission directly from the copyright holder. To view a copy of this licence, visit http://creativecommons.org/licenses/by/4.0/. The Creative Commons Public Domain Dedication waiver (http://creativeco mmons.org/publicdomain/zero/1.0/) applies to the data made available in this article, unless otherwise stated in a credit line to the data. 
multiple and targeted approaches involving a range of health workforce delivery models to provide support for those with chronic health conditions and co-morbidities, which in turn improves efficiency, reduces hospital admissions and improves the quality of life of the individual $[8,10,11]$.

Internationally, one health professional group experiencing rapid role expansion is the Nurse Practitioners (NP). The NP is a registered nurse with additional qualifications, authorised to integrate advanced nursing and medical clinical skills, to independently assess, diagnose, prescribe medications, and manage patients within an agreed scope of practice [9]. While the title protection, regulation, qualifications and scope of practice of the NP role differs across countries [9], in Australia, to be endorsed as an NP, the registered nurse candidate must hold a Master's degree and $5000 \mathrm{~h}$ or 3 year full-time specialised clinical experience [12-17]. The scope of the Australian NP practice includes: managing patient episodes of care, initiation and interpretation of diagnostic and pathology investigations, endorsement to prescribe medications, patient education and health promotion, admission and discharge rights and referrals for specific patient groups [10, 11, 18-21]. As increasingly more NPs are getting established in the Australian public sector workforce $[17,22]$ and to a lesser extent in the private, community and primary care settings [12], the question as to what patients want continues to emerge [23].

Internationally and in Australia, health service providers are reconceptualising how health care is delivered through adjunct, autonomous models of care, delivered by health professionals who work independently to manage caseloads and who are not a medical doctor $[9,14,21,24]$. Patient reported outcome measures such as patient experience and satisfaction are fundamental measure of quality health care [25]. Patient perception of care is important as satisfaction correlates with compliance, improved health outcomes and quality of life [23]. While consumer experience and satisfaction with the NP role is well documented in the international and Australian literature $[9,11,26-36]$, much of this evidence has been collected during or following NP consultations. Evidence is needed understanding consumer choice and public expectations or willingness to see different health practitioners. Indeed, authors caution that health care providers should not assume that all people are willing to receive autonomous health care from personnel such as NPs who are not an MD [37, 38].

The emerging international and Australian evidence is that the general public are willing to treated by health professionals who are not an MD in circumstances, where they would have traditionally only consulted the MD [39-41]. Circumstances included; minor ailments
[37] reduced waiting time for a consultation [37, 42]; and the extra time they receive from nurses [31, 34, 43-46]. Evidence from the U.S shows that once having treated solely by the NP, instead of an MD, 94\% patients reported a willingness to be seen by the NP on future visits [43]. Clarifying the nature of the consumers 'willingness' to be seen by health care workers warrants further investigation [38, 40, 42, 43, 47].

Australian studies have been undertaken to ascertain health-care consumers' willingness to be seen by an NP [40] and what level of independent treatment would they accept from the NP for their primary health care needs $[22,48]$. Parker et.al reported that Australian health consumers are supportive of the NP role to provide medical certificates, repeat prescriptions, and treat 'minor' or 'every day' health concerns [22, 48]. A limitation of Parker and colleagues' $[22,48]$ research is that the participants reported either limited or no prior experience of seeing seeking and receiving treatment from a health professional who is not an MD. Participants experienced confusion around role delineation and differences between nurse practitioners, other nurses and GPs [48].

In Australia, the NP role has only been in place for a relatively short period, achieving legislated title protection in 1998 [19] with current estimate of 1745 endorsed practitioners nationally [17]. Given this nascence, it is fair to assume that the public are not familiar with NP role and scope of practice. With the exception of Parker and colleagues' $[22,48]$ research, there is a paucity of empirical data focused on public willingness to be seen and treated by an NP. Exploring the general public's willingness to engage with an unfamiliar model of health care can potentially have important implications for service delivery [34]. The aim of this study was to contribute new knowledge in this field by examining the factors related to the general public's willingness to be seen and treated by an NP.

\section{Methods \\ Design}

This population-based cross-sectional survey of Australian residents sought to identify factors that predict the general public's willingness to be seen and seek treatment from an NP. Secondary aims were to determine:

- the proportion of the Australian population willing to be seen and treated by an NP,

- if socio-demographic factors (i.e., age, sex, education, location) of individual's willingness to be seen by an NP

- if waiting time reduction influences willingness to be seen and treated by an NP. 


\section{Sample}

The study was designed to create an estimation of the attitudes of Australian adults, 18 years and over, on the topic of interest $[49,51]$. The research team describes this technique in detail elsewhere $[50,52]$. For sampling purposes, Australia was stratified into state and territory areas and telephone numbers randomly selected using random digit dialing (RDD) databases supplied by Sampleworx Pty Ltd. Approximately $48 \%$ of the sample were contacted on a mobile telephone. To ensure equal representation of males and females, the sex of the potential participant was randomly selected prior to making the phone call. To be eligible, the participant has to be over the age of 18 years and be of the predetermined sex.

We used the most recent total population according to the Australian Bureau of Statistics August 2015 for $18+$ which was $18,182,764$. The sample size of 1318 was considered to be large enough to yield suitably precise estimates of prevalence rates of interest, with $95 \%$ confidence intervals of approximately $\pm 1.5 \%$.

\section{Survey measures}

The survey questions were developed from literature and existing survey $[26,48]$.

All data were collected by a research assistant, who read the questions to the participant over the telephone. Both the survey questions and data collector technique were pilot-tested (Table 1) with 40 randomly selected dwellings. Minor question and data collector script changes were made to increase validity by addressing inadequate responses and changing confusing wording. The survey consisted of a standardised introduction, demographic and core general health questions, seven closed-ended (Likert scale) questions specifically elicited information about willingness to see NP (Table 1) and two open-ended questions. Subsequent to participant consent to participate, the data collector asked if the person had heard of an NP, then they read out a description of the role of the NP (as outlined in Table 1) prior to proceeding. This description of the NP served to ensure all participants had same understanding of the role of the NP. During data collection, $10 \%$ of the data collectors were monitored for consistency.

Demographic variables included age, education, locality and sex. Multiple general health variables were also included; the number of days in the last month that health interfered with daily activities, days in poor physical health, days in poor mental health, and days in which sleep was inadequate. Health status responses were nominally coded; 0 days (0), 1-10 days (1), 11-20 days (2), and 21-30 days (3). Also included as predictors were general health ratings; poor (0), fair (1), good (2), and whether the individual was suffering from a chronic condition. The response variables that were not intrinsically binary were transformed as necessary for data analysis.

The interviewer also asked two open-ended questions "Could you briefly describe a situation and why you would /would not consider using a nurse practitioner?" Given the volume of the public responses to this qualitative component of the study, the findings are presented elsewhere [50]. This paper reports the quantitative responses from the survey.

\section{Data analysis}

NP attitude responses were measured using a five-point Likert scale and collapsed into two discrete categories;

\section{Table 1 Closed-ended survey questions about NP attitudes}

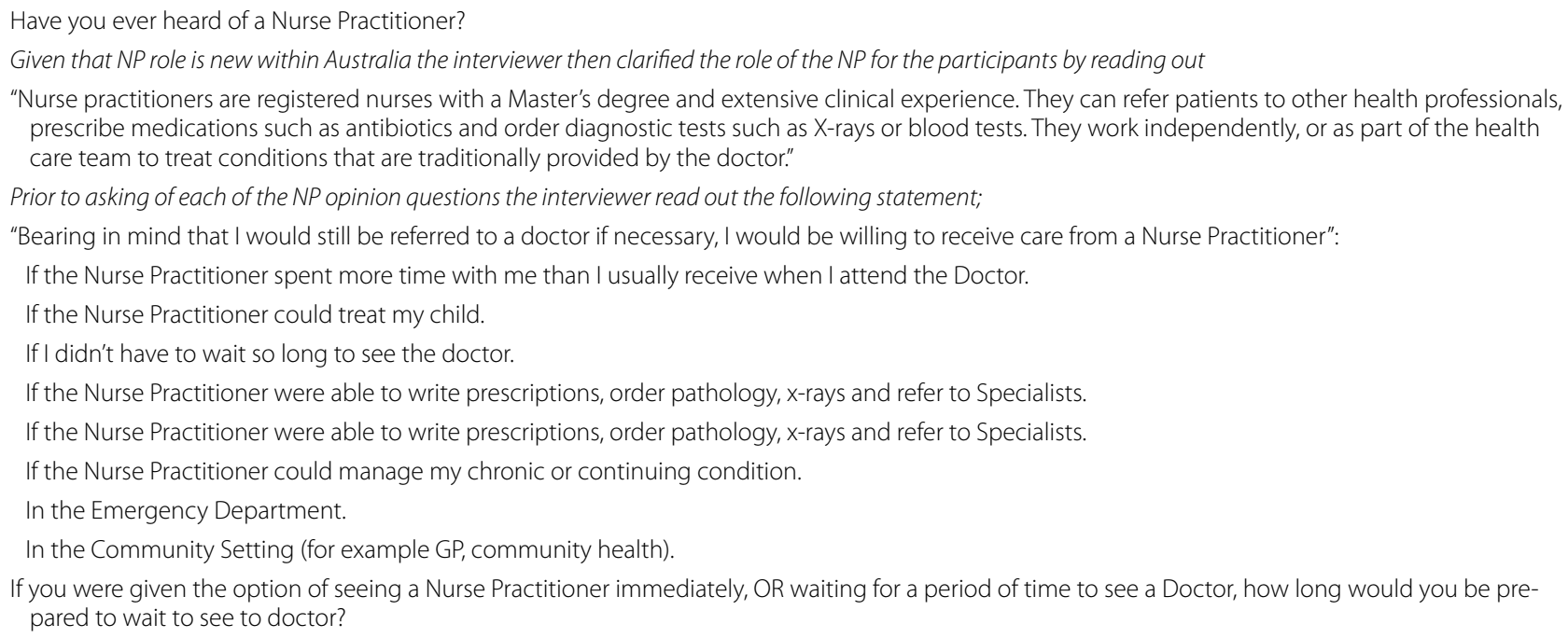


agree (agree/strongly agree) or fail to agree (neutral, disagree, strongly disagree) prior to analysis. On any given item, relatively few $(1.8 \%)$ respondents either did not know the answer or made no response. These nonresponses were treated as missing data and excluded from analyses on a variablewise basis. Descriptive statistics were used to describe demographic profiles and Wilcoxon rank sum test used to determine differences in willingness scores. We used $\mathrm{R}$ statistical package and conducted a series of exploratory logistic regressions to isolate significant demographic and health status predictors of the general public's willingness to see an NP. Stepwise backwards variable selection was performed, optimising the Akaike Information Criteria (AIC). This is a model selection technique that attempts to minimise the deviance (error) whilst maximising model parsimony (fewer predictors) [54]. Associations are presented as an odds ratio (OR) in comparison with a reference group and indicated the increased or decreased likelihood of a sub-group within the population to perform a specific behaviour. Statistical significance was set at $<0.05$.

\section{Results}

Of those eligible, 1318 (response rate 33\%) residents agreed to participate in the telephone survey, representing all Australian states and territories (Table 2) and slightly more females $(54.3 \%, n=716)$ than males $(45.7 \%, n=602)$. Reasons people declined to participate included, a reluctance to participate in telephone surveys; screening of calls; and the anticipated length of the survey (average total length of telephone survey $=33 \mathrm{~min}$ ). Most were born in Australia $(75 \%, n=989)$, in married/ de-facto relationships $(66.5 \% ; n=877)$, employed on full/part-time basis $(52.9 \% ; n=697)$ and held a technical or higher education qualification $(66.4 \% ; n=875)$. Just under a third were retired or on a pension $(29.2 \%$; $n=385$ ). The sample had a mean age of 52.6 years (SD $17.96)$ and range of $18-101$ years.

\section{Heard of nurse practitioner}

Overall, just over half $(53.3 \% ; n=703)$ of respondents had previously heard of an NP with $4 \%(n=46)$ were unsure whether they had or not. Within this group, two-thirds $(61 \% ; n=439)$ of female respondents had heard of an NP compared with less than half of the participating males $(44 \% ; n=264)\left(x^{2}=41.07, d f=1, p<001\right)$. Around twothirds of people over the age of 55 years $(58.8 \% ; n=379)$ and those with a tertiary education $(62.4 \% ; n=364)$ were also significantly more likely to have heard of a nurse practitioner (Table 2).
Table 2 Demographic profile $(n=1318)$

\begin{tabular}{|c|c|c|c|c|}
\hline \multirow{2}{*}{$\begin{array}{l}\text { Item } \\
\text { Total population }\end{array}$} & \multicolumn{2}{|c|}{$\begin{array}{l}n \% \\
\text { of total } \\
\text { sample }\end{array}$} & \multirow[t]{2}{*}{$\begin{array}{l}\% \text { of sample } \\
\text { heard of NP }\end{array}$} & \multirow[t]{2}{*}{$P$ value } \\
\hline & & & & \\
\hline \multicolumn{5}{|l|}{ Sex } \\
\hline Male & 602 & 45.7 & 43.9 & .001 \\
\hline Female & 716 & 54.3 & 61.3 & \\
\hline \multicolumn{5}{|l|}{ Age } \\
\hline 18-34 years & 255 & 19.3 & 43.9 & .003 \\
\hline $35-44$ years & 186 & 14.1 & 48.4 & \\
\hline $45-54$ years & 219 & 16.6 & 53.0 & \\
\hline 55 years and over & 645 & 48.9 & 58.8 & \\
\hline \multicolumn{5}{|l|}{ Highest level of education } \\
\hline Primary schooling or below & 26 & 1.9 & 48.3 & .001 \\
\hline Secondary/High School & 410 & 31.1 & 46.3 & \\
\hline $\begin{array}{l}\text { Technical studies or further } \\
\text { education }\end{array}$ & 292 & 22.2 & 45.9 & \\
\hline University or Tertiary & 583 & 44.2 & 62.4 & \\
\hline \multicolumn{5}{|l|}{ Australian State or Territory } \\
\hline Australian Capital Territory & 33 & 2.5 & 54.5 & .845 \\
\hline New South Wales & 380 & 28.8 & 52.9 & \\
\hline Northern Territory & 28 & 2.1 & 57.1 & \\
\hline Queensland & 271 & 20.6 & 50.6 & \\
\hline South Australia & 89 & 6.8 & 52.8 & \\
\hline Tasmania & 35 & 2.7 & 71.4 & \\
\hline Victoria & 347 & 26.3 & 53.6 & \\
\hline Western Australia & 131 & 9.9 & 53.4 & \\
\hline \multicolumn{5}{|l|}{ Rurality } \\
\hline City & 652 & 49.5 & 54.0 & .924 \\
\hline Town/regional & 321 & 24.4 & 51.7 & \\
\hline Rural & 345 & 26.2 & 53.7 & \\
\hline
\end{tabular}

\section{Willingness to receive care from the nurse practitioner}

The majority of the respondents agreed/strongly agreed that they were willing to be seen by the NP for a variety of health care scenarios. A total of $91.6 \%(n=1205)$ of respondents were willing to see an NP in a community treatment setting, whilst $75.1 \%(n=977)$ responded positively on the condition that the NP would spent more time with them than a doctor. Figure 1 compares variation in responses regarding willingness to receive care from an NP in various circumstances.

As each of these questions (Fig. 1) concerned willingness to utilise an NP, we considered whether it would be valid to aggregate the items in a single scale. The polychoric inter-correlations of these items ranged between 0.60 and 0.80 , and the Mokken scalability coefficient $H$ for the entire scale was 0.64 , well above the recommended threshold of 0.30 [53, 54]. Accordingly, we calculated a mean 'willingness to receive care from an NP' score for each participant from the seven items (Fig. 1). 


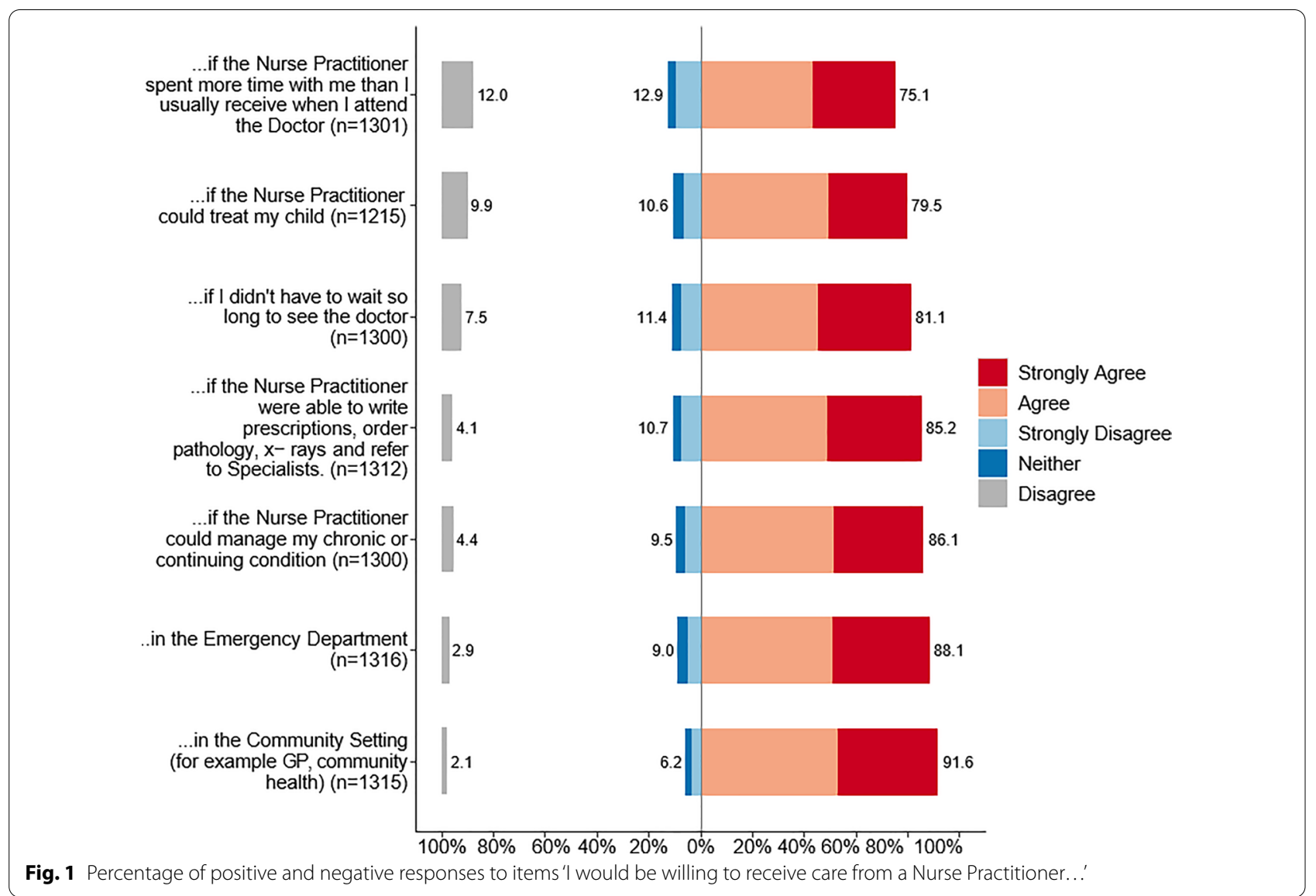

There was no relationship between having previously heard of an NP and willingness to receive care, both those who had $(\mathrm{M}=4.07, \mathrm{SD} .83)$ and those who had not $(M=4.05$, SD 0.775$)$ had a mean response close to 'Agree' (Wilcoxon rank sum test $W=195,250, p=0.461$ ). Older respondents tended to be less willing to see an NP (Spearman $r=-0.15)$. While not statistically significant $(p=0.064)$ women $(M=4.11$; SD 0.80$)$ were slightly more willing to see an NP than men $(M=4.02$, SD.79).

\section{Reduced wait time}

The majority $(60.2 \%, \mathrm{n}=745)$ of respondents preferred to see an NP immediately rather than having to wait to see the MD. A small proportion $(2.5 \%, n=31)$ of participants would prefer to wait over $4 \mathrm{~h}$ to be seen by an MD or would not see an NP under any circumstances (3.6\%, $N=45$ ) (see Fig. 2). 640 participants (48.6\%) affirmed that there were situations in which they would not consider an NP. Yet, another 641 respondents (48.6\%) indicated that they would always consider an NP and $6 \%$ did not respond or were unsure.

In the interest of understanding whether the personal factors that might affect attitudes to being seen by an NP, we conducted a series of exploratory logistic regressions on each of the NP-willingness related items, predicting (Agree [1] versus Disagree/Neutral [0]. These categories were combined due to their relatively low prevalence. Factors that best predict willingness to be seen by the NP are presented in Table 3 . When controlling for these variables, the logistic regressions demonstrated that those over the age of 65 years (older respondents), when compared to all other age groups, were more likely to have heard of NPs, they were also less willing to receive care from an NP regardless of the service, even if they could see the NP sooner (Table 3, row 3). This older group of respondents were also more willing to wait longer periods of time to see a doctor. Interestingly, older respondents were also the cohort most likely to always consider an NP. In contrast, respondents from rural areas, when compared to people from cities, are more likely to always consider NP for prescriptions and referrals and to manage their chronic illness (Table 3, columns 4, 6). They were also less likely to want to wait to receive care from the MD. There were no observed differences in willingness to receive care from the NP between respondents who identified as having poorer physical health, mental 


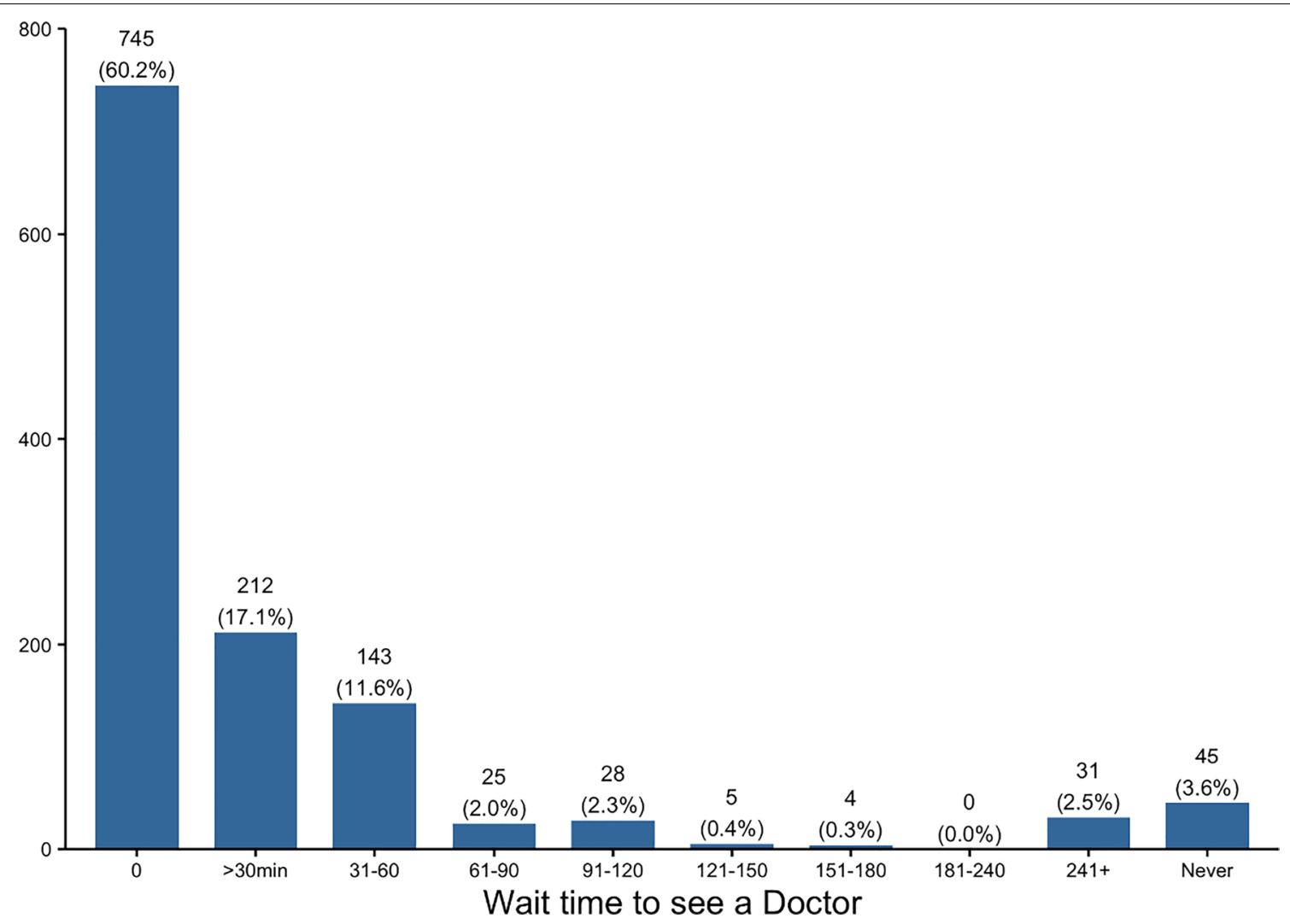

Fig. 2 Duration of time willing to wait to see an MD in preference to an NP. Zero (0) indicates preference to see an NP immediately

health or a chronic disease compared to those who did not identify with the having these lower general health variables (Table 3 , rows 12, 13).

\section{Discussion}

This study provides confirmation of the general publics' willingness to be seen and treated by an NP. When provided with information about NPs scope of practice, there was strong overall public support for this role across different demographic groups. Despite limited awareness of the role, the proportion of the Australian population in this study willing to be seen and treated by an NP was high. The majority reported high levels of willingness to be seen and treated by an NP (80-91.5\%) in the community, the emergency department, to manage chronic conditions, to have scrips written and referrals made, and if they did not have to wait so long to see a medical doctor (MD). The main factors that predict greater willingness to be seen and receive treatment from an NP were being: female, under 65 years of age, a native English speaker, and a rural resident. Offering individuals immediate assessment by an NP as opposed for waiting for an MD review did improve the willingness to be seen and treated by an NP; however, this cannot be applied to all medical contexts.

This study indicates that the Australian public have limited awareness of the NP role with only half of the sample having heard of an NP, a finding consistent in contemporary literature $[22,48]$. This is not surprising given the general publics' limited understanding of the different categories nurses or levels within nursing groups [26, 49], the relatively low number of NPs (approximately 0.5\% of the nursing workforce $[14,55]$ ) and the fact that the majority of NPs in Australia are predominantly employed in the public sector [1]. International cross-country comparisons suggest that public exposure to the NP role will also be influenced by the fact that there are only 4.4 NPs per 100,000 population compared with 395 physicians per 100,00 population [14]. While the number of NPs nationally and internationally is slowly increasing $[11,14$, 56], there is a risk that the general public, in failing to recognise the extended scope of the NP role in comparison to other nurses, nor their ability to independently manage a case load, may fail to recognise the NP role as a skilled and viable model for transforming health care delivery across Australia. In our study, we found that while there is limited understanding of the NP role amongst the 


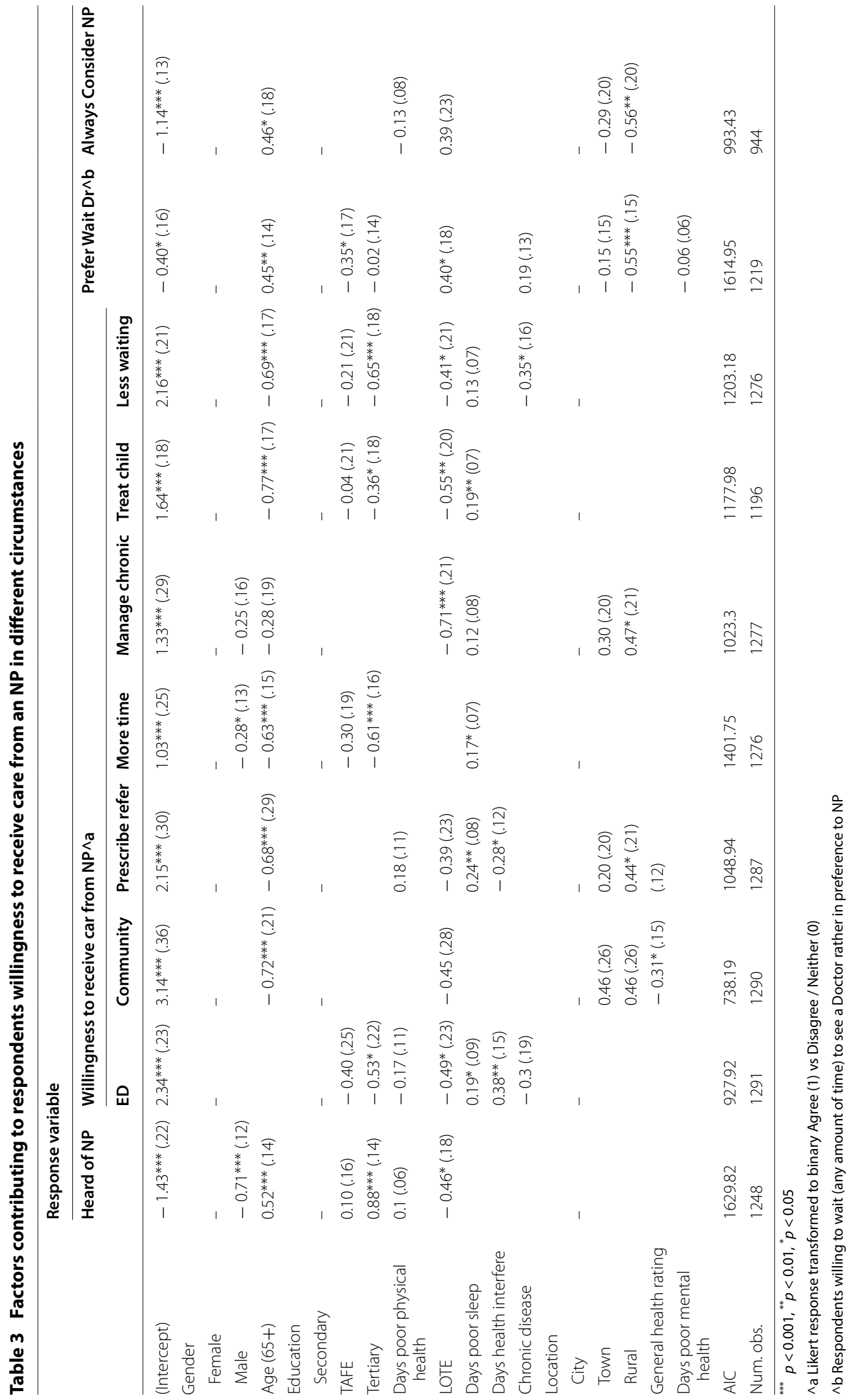


Australian public, this had no relationship to their willingness to receive treatment and autonomous episodes of care from an NP. Indeed, a recent international scoping review of patient satisfaction with independent care provided by adjunct health care providers, such as the physician assistants, found that people are generally satisfied with care received, regardless of medical provider [23]. Health care consumer support, willingness and acceptance for autonomous and complementary models of health care are fundamental to informing policy change [24]. Our study affirms that the Australian public are very accepting of the NP model of care. This high level of acceptance is potentially related to the general public's confidence in the governance of health the system to adequately educate the NP for the role [50].

In Australia, few NPs are employed in primary care and community settings $[12,17]$, and this fact provides context as to why only half of the participants had heard of the NP. Regardless of this limited awareness, no differences observed between respondents with a prior experience of accessing consultations with NPs and those without. Indeed, nearly, all (91.6\%) of the participants in our study were willing to see an NP in a community setting. Our findings suggest that Australian public are open to independent nursing led models to access community and primary health care services and this was more evident in the younger population (less than 65 years of age). We also found that willingness to access the NP in the community setting $(91.5 \%)$ and to manage a chronic illness $(88 \%)$ were both very high. Maier et al. [14] proposed that $67-93 \%$ of primary health care services and visits can be delivered safely by an NP. This observation contrasts with Parker et al. study [22] who found that the management of chronic or long-term conditions was considered only moderately acceptable within the scope of an NP. A possible explanation for those over the age of 65 (when compared to all other age groups) being less willing to see an NP may well be related to the stero-typical understandings held by this age group and the legacy of the subservient role of the nurse to the MD [24]. Alternative explanations may be the Australian health-care consumers' inexperience with the NP as an independent consultant for primary health care concerns and availability of and access to health care.

A cited feature of NP practice is longer consultations, of around $1 \mathrm{~h}$ in duration, allowing time for patients and their families to feel heard and listened to [31]. Arguably, these longer consultations have influenced patient satisfaction, their ability to understand, manage and cope with their illness $[31,45,46]$. Patient enablement has been attributed to the processes within the NP consultation, such as: the use of longer consultation times, the building of partnerships between NPs and patients, and through NPs' holistic and hands-on consultation approach. Other studies report the longer consultation times improve patient adherence to treatment plans, positively impact changes in health behaviours [31] and improved service delivery [57]. Despite these espoused correlations between extended consultation times and reported patient satisfaction, we found that spending more time during consultations was not a contributing factor to willingness to be see an NP. A recent study found that NPs do not have lengthy consultation times, rather they convey a sense that they are spending more time during consultations [55]. Indeed, no correlation was found between the length of NP consultations and post-consultation consumer satisfaction or enablement [55]. These authors concluded, it is the consumers' expectations and extent the NPs can make autonomous diagnostic and prescribing decisions that positively impact postconsultation enablement.

Timely access to health care is important, with $89 \%$ of those surveyed stating they were willing to be seen by the NP immediately rather than having to wait for over an hour to be seen by the medical doctor (MD). Similar findings were reported by Parker and colleagues [48]. Furthermore, in our study, people from regional towns and rural locations were significantly more likely to prefer to see the NP immediately as opposed to having to wait for the MD. This observation may reflect the difficulties people from these regional and rural settings experience accessing timely health care. Shortages of skilled health care workers, particularly specialist physicians, are widespread in rural and remote communities [14]. The geographical imbalances of access to health care means rural residents must either wait or travel some distances to access specialist services. NPs are well positioned to address this deficit and fill the service gap [58]. One part of the impetus for establishing NP roles in Australia was to increase patient access to care specifically in rural and remote settings [10].

In 2010 in Australia, the legal scope of the Australian NP practice was expanded to include ability to register consumers to access the Medicare Benefit Schedule (MBS) and the Pharmaceutical Benefits Scheme (PBS) [11]. These schemes ensure the NP can receive remuneration for specific services on the Schedule list $[10,57]$. While NPs eligibly for MBS and PBS have facilitated the growth of independent (private) NP services the, restrictive nature of the MBS items is counterproductive, limiting the level of remuneration available, increasing the cost of NP service, and ultimately the general public's acceptance of and utilisation of NP services [12, 17, 59, 60]. The design of the MBS and PBS and the mandate that NPs must establish collaborative arrangement with an MD or an establishment that employs MDs [17] are 
significant barriers to NP providing complete episodes of care, reducing their capacity to function autonomously [12]. Reviewing of or removing these mandated collaborative arrangements and extending access to MBS/ PBS items will ensure NPs are able to function at their full capacity and thus improving access to care to reach underserved populations [7, 17]. The general public are accepting of the NP model of care as a means for accessing autonomous, safe and efficient health care, particularly when there are gaps in existing health services such as primary health care and in smaller towns or rural settings.

\section{Limitations}

All survey research is limited by the nature of being self-reported. Of those who passively declined participation in the study, many may not have answered their phone due to screening of spam telephone calls or numbers that are unknown. Some may not have had mobile phone reception coverage or may not have been home at the time of the landline call. This sampling bias was accounted and corrected for with the use of data weighting of the results. Survey questions designed to be short and concise may have limited the respondent's understanding of what was being asked and impact the quality of their response. In addition, the anonymity of participation in telephone surveys may bias outcomes [61]. Finally, providing the respondent with information about the NP role during the survey may have inadvertently contributed to informing their response.

\section{Conclusions}

We found that the general public are overwhelmingly accepting of the NP model of care as means of increasing access to health services. Furthermore, the persons level of acceptance varies depending on their personal health circumstances, age and health status. This was more evident for people from smaller towns and rural settings, if accessing the NP services meant accessing care sooner. Given the NP role was introduced to fill gaps in health service and increase access to health care services for underserviced populations such as rural settings, it is now time to cease the rhetoric and support this highly skilled workforce to practise autonomously to meet public expectations.

\footnotetext{
Abbreviations

MD: Medical Doctor, broad term including general practitioners, physicians and hospital doctors; NP: Nurse Practitioner.
}

\section{Acknowledgements}

Included the cover letter.

\section{Author contributions}

Included the cover letter. All authors read and approved the final manuscript.

\section{Funding}

This research was funded by the Population Research Grant Scheme (PRGS),

School of Human, Health and Social Sciences, Population Research Laboratory.

\section{Availability of data and materials}

The datasets used and/or analysed during the current study are available from the corresponding author on reasonable request.

\section{Ethics approval and consent to participate}

The data collectors signed statements of confidentiality and privacy prior to the commencement of the study. The respondents gave verbal informed consent at the beginning of the telephone interview.Ethics approval was received (Number-H14/09-203; National Survey 2015) from the University Human Research Ethics Committee prior to data collection. Participants were notified of the voluntary nature of participation and given the opportunity to withdraw or refuse to answer any of the questions. The researchers were guided by The National Statement on Ethical Conduct in Human Research [62]. Ethical principles of research merit and integrity, justice, beneficence and respect have been upheld by the researchers.

\section{Consent for publication}

Consent for publication in the BMC Human Resources for Health has been given by the authors of this article.

\section{Competing interests}

The authors do not have any conflicts of interest to declare.

\section{Author details}

${ }^{1}$ CQUniversity Australia, Building 18 Rockhampton Campus, Bruce Highway, Rockhampton Q 4702, Australia. ${ }^{2}$ School of Nursing, Midwifery and Paramedicine, University of the Sunshine Coast, 90 Sippy Downs Drive, Sippy Downs Q 4556, Australia. ${ }^{3}$ CQUniversity Australia, University Drive, Building 8/G.47, Branyan Australia, Bundaberg, Qld 4670, Australia.

Received: 1 June 2020 Accepted: 1 February 2021

Published online: 17 February 2021

\section{References}

1. Carter MA, Owen-Williams E, Della P. Meeting Australia's emerging primary care needs by nurse practitioners. J Nurse Pract. 2015;11(6):647-52. https://doi.org/10.1016/j.nurpra.2015.02.011.

2. Toloo S, FitzGerald G, Aitkin P, Ting J, Tippett V, Chu K. Emergency Health Services (EHS): demand and service delivery models. Monograph 1: literature review and activity trends. Brisbane: Queensland University Technology; 2011.

3. Duffield CM, Conlon L, Kelly M, Catling-Paull C, Stasa H. The emergency department nursing workforce: Local solutions for local issues. IntEmergNurs. 2010;18(4):181-7.

4. Jennings N, O'Reilly G, Cameron P, Free B, Bailey M. Evaluating outcomes of the emergency nurse practitioner role in a major urban emergency department, Melbourne Australia. J ClinNurs. 2008;19:1044-50.

5. Lee G, Jennings N. A comparative study of patients who did not wait for treatment and those treated by Emergency Nurse Practitioners. AustralasEmergNurs J. 2006;9:179-85.

6. Lowthian J, Curtis A, Stoelwinder J, McNeil J, Cameron P. Emergency demand and repeat attendances by older patients. Intern Med J. 2013;43(5):554-60.

7. Ervin K, Reid C, Moran A, Opie C, Haines H. Implementation of an older person's nurse practitioner in rural aged care in Victoria, Australia: a qualitative study. Hum Res Health. 2019;17(1):80. https://doi.org/10.1186/ s12960-019-0415-z.

8. Chavez KS, Dwyer AA, Ramelet A-S. International practice settings, interventions and outcomes of nurse practitioners in geriatric care: a scoping review. Int J Nurs Stud. 2018;78:61-75.

9. Schober M. Guidelines on Advanced Practice Nursing 2020. International Council of Nurses. 2020, Geneva Switerland. https://www.icn.ch/system/ 
files/documents/2020-04/ICN_APN\%20Report_EN_WEB.pdf.Accessed 15 Feb 2021

10. Currie J, Chiarella M, Buckley T. Collaborative arrangements and privately practising nurse practitioners in Australia: results from a national survey. Aust Health Rev. 2017:41(5):533-40.

11. Currie J, Chiarella M, Buckley T. Practice activities of privately-practicing nurse practitioners: results from an Australian survey. Nurs Health Sci. 2018;20(1):16-23.

12. Currie J, Chiarella M, Buckley T. Privately practising nurse practitioners' provision of care subsidised through the medicare benefits schedule and the pharmaceutical benefits scheme in Australia: results from a national survey. Aust Health Rev. 2019;43(1):55-61.

13. Cashin A, O'Connell J, Christofis L, Lentakis A, Rossi M, Crellin D. Clinical initiative nurses and nurse practitioners in the emergency department: what's in a name? AustEmergNurs. 2007;10(2):73-9.

14. Maier CB, Barnes H, Aiken LH, Busse R. Descriptive, cross-country analysis of the nurse practitioner workforce in six countries: size, growth, physician substitution potential. BMJ Open. 2016;6(9):e011901.

15. Morilla-Herrera JC, Garcia-Mayor S, Martín-Santos FJ, KaknaniUttumchandani S, Leon Campos Á, Caro Bautista J, et al. A systematic review of the effectiveness and roles of advanced practice nursing in older people. Int J Nurs Stud. 2016;53:290-307.

16. Middleton S, Gardner A, Della PR, Lam L, Allnutt N, Gardner G. How has the profile of Australian nurse practitioners changed over time? Collegian. 2016;23(1):69-77. https://doi.org/10.1016/j.colegn.2014.10.004.

17 Chiarella E, Currie J, Wand T. Liability and collaborative arrangements for Nurse Practitioner practice in Australia. AustHelath Rev . 2019. https://doi. org/10.1071/AH19072.

18. Australian Nursing and Midwifery Board A. Registration standard for endorsement of nurse practitioners. 2010. http://www.nursingmidwifer yboard.gov.au/Health-Professions/Nursing-and-Midwifery/RegistrationStandards.aspx. Accessed 2010.

19. Helms C, Gardner A, McInnes E. Consensus on an Australian nurse practitioner specialty framework using delphi methodology: results from the CLLEVER 2 study. J AdvNurs. 2017;73(2):433-47.

20. Queensland Government. Queensland Nurse Practitioner: implementation guide. In: Queensland Health, editor: Brisbane: Queensland Government; 2008.https://www.health.qld.gov.au/ocnmo/nursing/nurse-pract itioners. Accessed Jan 2021.

21. Wilson A, Zwart E, Everett I, Kernick J. The clinical effectiveness of nurse practitioner' management of minor injuries in an adult emergency department: a systemic review. Int J Evid Based Health Care. 2009;7:3-14.

22. Parker R, Forrest L, McCracken J, McRae I, Cox D. What primary health-care services are Australian consumers willing to accept from nurse practitioners? A National Survey. Health Expect . 2014;17(5):733-40.

23. Hooker RS, Moloney-Johns AJ, McFarland MM. Patient satisfaction with physician assistant/associate care: an international scoping review. Human Res Health. 2019;17(1):104.

24. Paddison CA, Abel GA, Burt J, Campbell JL, Elliott MN, Lattimer V, et al. What happens to patient experience when you want to see a doctor and you get to speak to a nurse? Observational study using data from the English General Practice Patient Survey. BMJ open. 2018;8(2):e018690.

25. Australian Commission on Safety and Quality in Health Care (ACSQHC). About PROMs. Australian Commission on Safety and Quality in Health Care, Australian Government. 2019. https://safetyandquality.govcms.gov. au/our-work/indicators-measurement-and-reporting/patient-reportedoutcomes/about-proms\#why-are-proms-used? Accessed 2020.

26. Allnutt J, Allnutt N, McMaster R, O'Connell J, Middleton S, Hillege S, et al. Clients' understanding of the role of nurse practitioners. Aust Health Rev. 2010;34(1):59-65. https://doi.org/10.1071/ah09688.

27. Byrne G, Richardson M, Brunsdon J, Patel A. An evaluation of the care of patients with minor injuries in emergency settings. AccidEmergNurs. 2000;8(2):101-9.

28. Parker RM, Desborough JL, Forrest LE. Stakeholder perceptions of a nurse led walk-in centre. BMC Health Serv Res. 2012;12(1):382-8. https://doi. org/10.1186/1472-6963-12-382.

29. Roche TE, Gardner G, Lewis PA. Effectiveness of an emergency nurse practitioner service for adults presenting to rural hospitals with chest pain: protocol for a multicentre, longitudinal nested cohort study. BMJ Open. 2015;5(2):e006997.
30. Wilson A, Shifaza F. An evaluation of the effectiveness and acceptability of nurse practitioners in an adult emergency department. Int J NursPract. 2008:14:149-56.

31. Bentley M, Stirling C, Robinson A, Minstrell M. The nurse practitioner-client therapeutic encounter: an integrative review of interaction in aged and primary care settings. J AdvNurs. 2016;72(9):1991-2002. https://doi. org/10.1111/jan.12929.

32. Jennings $N$, Lee $G$, Chao K, Keating S. A survey of patient satisfaction in a metropolitan emergency department: comparing nurse practitioners and emergency physicians. Int J NursPract. 2009;15(3):213-8.

33. Jennings N, Clifford S, Fox AR, O'Connell J, Gardner G. The impact of nurse practitioner services on cost, quality of care, satisfaction and waiting times in the emergency department: a systematic review. Int J Nurs Stud. 2015;52(1):421-35.

34. Jakimowicz S, Stirling C, Duddle M. An investigation of factors that impact patients' subjective experience of nurse-led clinics: a qualitative systematic review. J ClinNurs. 2015;24(1-2):19-33.

35. Martin-Misener R, Donald F, Wickson-Griffiths A, Akhtar-Danesh N, Ploeg J, Brazil K, et al. A mixed methods study of the work patterns of full-time nurse practitioners in nursing homes. J ClinNurs. 2015;24(9-10):1327-37. https://doi.org/10.1111/jocn.12741.

36. Davey R, Clark S, Goss J, Parker R, Hungerford C, Gibson D. National evaluation of the nurse practitioner-aged care models of practice initiative: summary of findings. Centre for research \& action in public health. Canberra: UC Health Research Institute, University of Canberra; 2015.

37. Moser M. Attitude of emergency department patients with minor problems to being treated by a nurse practitioner. CJEM. 2004;6(4):246-52. https://doi.org/10.1017/S1481803500009209.

38. Larkin GL, Hooker RS. Patient willingness to be seen by physician assistants, nurse practitioners, and residents in the emergency department: does the presumption of assent have an empirical basis? Am J Bioeth. 2010;10(8):1-10. https://doi.org/10.1080/15265161.2010.494216.

39. Dill MJ, Pankow S, Erikson C, Shipman S. Survey shows consumers open to a greater role for physician assistants and nurse practitioners. Health Aff (Millwood). 2013;32(6):1135-42.

40. Hooker R, Harrison K, Pashen D. Are Australians willing to be treated by a physician assistant? Australias Med J. 2010;3(7):407-13. https://doi. org/10.4066/AMJ.2010.325.

41. Laurant MG, Hermens RP, Braspenning JC, Akkermans RP, Sibbald B, Grol RP. An overview of patients' preference for, and satisfaction with, care provided by general practitioners and nurse practitioners. J ClinNurs. 2008:17(20):2690-8

42. Kuilman L, Nieweg RM, van der Schans CP, et al. Are Dutch patients willing to be seen by a physician assistant instead of a medical doctor? Hum Res Health. 2012;10(28):1-8. https://doi.org/10.1186/1478-4491-10-28.

43. Maul TM, Zaidi A, Kowalski V, Hickey J, Schnug R, Hindes M, Cook S. Patient preference and perception of care provided by advance nurse practitioners and physicians in outpatient adult congenital clinics. Congenit Heart Dis. 2015;10(5):E225-9. https://doi.org/10.1111/chd.12273.

44. Eley DS, Patterson E, Young J, Fahey PP, Del Mar CB, Hegney DG, et al. Outcomes and opportunities: a nurse-led model of chronic disease management in Australian general practice. Aust J Prim Health. 2013;19(2):150-8. https://doi.org/10.1071/PY11164.

45. Frost J, Currie MJ, Cruickshank M, Northam H. Using the lens of enablement to explore patients' experiences of nurse practitioner care in the primary health care setting. Collegian. 2018;25(2):193-9. https://doi. org/10.1016/j.colegn.2017.06.002.

46. Frost JS, Currie MJ, Northam HL, Cruickshank M. The experience of enablement within nurse practitioner care: a conceptual framework. J Nurse Pract. 2017;13(5):360-7. https://doi.org/10.1016/j.nurpra.2017.01.002.

47. Hoskins R. Evaluating new roles within emergency care: a literature review. IntEmergNurs. 2010;19(3):125-40.

48. Parker R, Forrest L, Ward N, McCracken J, Cox D, Derrett J. How acceptable are primary health care nurse practitioners to Australian consumers? Collegian. 2013;20:35-41.

49. Evans H, Chappell R, Wright E. Using the Omnibus Survey to test questions on emigration. Popul Trends. 2007;127:15-9.

50 Craswell A, Dwyer T. Reasons for choosing or refusing care from a Nurse Practitioner: Results from a national population-based survey. J AdvNurs. 2019;75:3668-76. 
51. CQUniversity Australia Population Research Laboratory. National Social Survey 2015 (NSS-2015). Rockhampton: CQUniversity; 2015.

52. Dwyer TA. Predictors of public support for family presence during cardiopulmonary resuscitation: a population based study. Int J Nurs Stud. 2015;52:1064-70. https://doi.org/10.1016/j.jijnurstu.2015.03.004.

53. Kuijpers RE, Van der Ark LA, Croon MA. Standard errors and confidence intervals for scalability coefficients in Mokken scale analysis using marginal models. Sociol Methodol. 2013;43:42-69.

54 Mokken RJ. A theory and procedure of scale analysis with applications in political research. New York: Walter de Gruyter (Mouton); 1971.

55. Barratt J, Thomas N. Nurse practitioner consultations in primary health care: a case study-based survey of patients' pre-consultation expectations, and post-consultation satisfaction and enablement. Prim Health Care Res Dev. 2019. https://doi.org/10.1017/S1463423618000415.

56. Lowe G, Plummer V, Boyd L. Integration of nurse practitioners using a change management framework: the way forward. Aust Health Rev. 2017:41(5):553-60.

57. Dwyer T, Craswell A, Rossi D, Holzberger D. Evaluation of an aged care nurse practitioner service: quality of care within a residential aged care facility hospital avoidance service. BMC Health Serv Res. 2017;17(1):33. https://doi.org/10.1186/s12913-017-1977-x.
58. Spetz J, Skillman SM, Andrilla CHA. Nurse practitioner autonomy and satisfaction in rural settings. Med Care Res Rev. 2017;74(2):227-35.

59. Desborough J, Parker R, Forrest L. Nurse satisfaction with working in a nurse led primary care walk-in centre: an Australian experience. Aust $J$ AdvNurs. 2013;31(1):11-9.

60. Smith T, McNeil K, Mitchell R, Boyle B, Ries N. A study of macro-, meso-and micro-barriers and enablers affecting extended scopes of practice: the case of rural nurse practitioners in Australia. BMC Nurs. 2019;18(1):14.

61. Kreuter F, Presser S, Tourangeau R. Social desirability bias in CATI, IVR, and web surveys. Public Opin Q. 2008;72(5):847-65.

62. National Health and Medical Research Council. National Statement on Ethical Conduct in Human Research 2007 (Updated 2018). In: Australian Research Council and Universities Australia, editor. Commonwealth of Australia, Canberra 2018. https://www.nhmrc.gov.au/about-us/publicatio ns/national-statement-ethical-conduct-human-research-2007-updat ed-2018. Accessed Jan 2021.

\section{Publisher's Note}

Springer Nature remains neutral with regard to jurisdictional claims in published maps and institutional affiliations.
Ready to submit your research? Choose BMC and benefit from:

- fast, convenient online submission

- thorough peer review by experienced researchers in your field

- rapid publication on acceptance

- support for research data, including large and complex data types

- gold Open Access which fosters wider collaboration and increased citations

- maximum visibility for your research: over $100 \mathrm{M}$ website views per year

At BMC, research is always in progress.

Learn more biomedcentral.com/submissions 